Journal of Development and Communication Studies, Vol. 5. No. 2, July 2017 - June 2018 ISSN (Online \& Print): 2305-7432.

http://www.devcomsjournalmw.org.

\title{
Determinants of adoption of open defecation-free (ODF) innovations: A case study of Nadowli-Kaleo district, Ghana
}

\author{
Amin Alhassan \& Bismark K. Anyarayor \\ Department of Communication, Innovation and Technology, University for Development Studies, Tamale, Ghana \\ Author Email: hassanamin@,uds.edu.gh
}

\begin{abstract}
This study investigated the adoption of sanitation innovations introduced in Nadowli-Kaleo District in Upper West Region of Ghana as part of the efforts to attain open defecation free (ODF) status. The study follows a Community Led Total Sanitation (CLTS) programme implementation in the district in which less than half of the households in the community adopted the ODF innovations introduced. It explored why some community members adopt ODF innovations and why others do not. The study also investigated factors that determined continued use of the innovations and the effects of sustained adoption on the community. A qualitative research design was used to gather data from 252 households across seven area councils in the Nadowli-Kaleo District. An interview instrument was used together with, non-participant observation and key informant interviews to collect qualitative data. The study established that: while effective communication of innovation resulted in widespread awareness, low income levels significantly accounted for households' inability to sustain and utilize latrines. Other factors that influenced sustainable adoption of ODF innovations are the health and security advantages as well as the comfort and dignifying experience of privacy. In addition, cultural beliefs contributed to low levels of attitudinal change resulting in resistance to the adoption and sustainable use of ODF innovations. We recommend that future ODF programs based on CLTS module should intensify behaviour change communication (BCC) strategies such as interpersonal communication, mass media and role-play to bring about attitudinal change after the creation of awareness.
\end{abstract}

Key words: Sanitation, Community Led Total Sanitation, Innovation, Open Defecation (OD), Open Defecation Free (ODF), Triggering, Ghana

\section{https://dx.doi.org/10.4314/jdcs.v5i2.4}

(C) 2018. The Authors. This work is licensed under the Creative Commons Attribution 4.0 International License (CC-By-NC-ND). Users may freely share and redistribute this work provided that the author and the Journal of Development and Communication Studies are fully acknowledged. Users may not tweak or remix and offer this work for sale. The full license may be accessed at https://creativecommons.org/licenses/by-nc-nd/4.0/ 


\section{Introduction}

Good sanitation practices are essential for the attainment of sustainable development and poverty reduction. Indeed, the UN Sustainable Development Goal six identifies clean water and sanitation as a key objective for the global development community to work towards. The significance of improved sanitation in safeguarding the health and well-being of communities has been well researched (Cairncross, 2003; Jenkins \& Scott 2006; Moe \& Rheingans, 2006; WaterAid, 2017). Countries in the Global South have sanitation as a major developmental challenge, which has impacted negatively on the progress in health, gender equity, and socio-economic development (UNICEF, 2009). WaterAid, an international NGO estimates that 2.5 billion people including 840 million children do not use improved sanitation facilities and therefore practice open defecation. WaterAid ranks Ghana among the ten countries in the world with the worst statistical record on access to improved sanitation facilities. It says that 85.7 per cent of Ghanaians do not have access to basic sanitation facilities (WaterAid 2017, 6). Open defecation threatens public health, leads to high expenditure on health care, impacts negatively on social economic development and increases levels of poverty among rural societies where it is mostly practiced (UNICEF, 2009). In Africa, the number of people in rural areas without improved water supply and sanitation is six times higher than in urban populations (Baur \& Woodhouse, 2009; JMP, 2017, 35).

Water and sanitation issues are intertwined because contaminated water may result in water borne diseases, such as viral hepatitis, typhoid, cholera, dysentery and other diseases that cause diarrhoea. Repeated diarrhoea cases are an underlying cause of malnutrition, leading to weakened immune systems and impaired growth of human development. Women, adolescent girls, children and infants suffer tremendously from the use of unclean water, inadequate hygiene and sanitation facilities (UNICEF, 2009; WaterAid, 2017; JMP, 2017).

A Water and Sanitation Programme (WSP) report on Economic Impact of Poor Sanitation in Africa (WSP, 2012), indicated that poor sanitation cost Ghana GHS 420 million equivalent to US $\$ 290$ million. This represents 1.6 percent of national Gross Domestic Product (GDP). The poor state of sanitation of the country has a direct relation with the health status of the population. According to a Ghana Health Service (GHS) 2016 report, Ghana Factsheets of Health Statistics, malaria and diarrhoea are the first and fourth major causes of death among children under five years of age accounting for 26 percent and 9 percent respectively in 2008. The report also reveals that malaria accounted for 11 percent and diarrhoea 5 percent in 2002 of all deaths of all age categories in the country (GHS, 2016, 33). Though there is a direct relation between improved sanitation and improved health, the age of total expenditure of GDP on health far exceeds the government's 0.5 percent commitment of total expenditure of GDP on sanitation. This implies that Ghana focuses more on curative health care than on preventive health care.

If Ghana is to meet the UN Sustainable Development Goal six, a fundamentally new approach to sanitation will be needed. Government of Ghana and other non-governmental organizations used several strategies to address open defecation problems in rural communities. Supply-led, demand-responsive and private good component of sanitation were some of the strategies adopted and used in Ghana (Kleemeier, 2001; Wellington, Larbi \& Appiah, 2011).

From 2007, the Government of Ghana and NGOs in water and sanitation sector in Ghana began using the Community-Led Total Sanitation (CLTS) strategy (MLGRD \& MWRWH, 2009). CLTS was pioneered by Kamal Kar, an independent development consultant from India in 1999 and was initiated in Africa in 2002 after some two trainings sessions in Tanzania and Ethiopia (IIED, 2010). CLTS seek to spur community members to action through an 'ignition' moment when they are 'triggered' by collectively realizing that open defecation amounts to eating each other's faeces. Also CLTS is an integrated approach to achieving and sustaining open defecation free status. Embedded in CLTS is the facilitation of the communities' own analysis of their practices of defecation and consequences, culminating in collective action to attain Open Defecation Free (ODF) environment. Under the CLTS program communities are not 
offered financial support nor subsidies to assist them acquire their own facilities. It is an awareness creation and attitude change process to trigger self-initiated efforts to seek solutions to the absence of household sanitation convenience.

As a supporting component to the awareness creation and attitude transformation process, publicly accessible space, called water and sanitation market or "sani-mart" is created. At the sani-mart diverse technological options for providing improved latrines are displayed for community members to choose the option they have financial capacity to construct and also fit their local conditions. Mukherjee, et.al (2012, 124) defined sanitation market as "the use of marketing principles to generate demand and facilitate supply of improved sanitation, thereby increasing uptake. It includes understanding the target market using formative research and supply capacity assessment, developing behaviour change communication strategies, and getting the marketing mix right, thus, product, price, place and promotion." CLTS strategy is meant to inculcate changed behaviours towards practicing good sanitation, and personal hygiene (Kar \& Chambers, 2008). Furthermore, CLTS is to stimulate positive household response to construct and use household latrines so as to improve sanitation conditions, human health, economic, and social development.

\section{Statement of the problem}

The 2010 Ghana Population and Housing Census (GSS, 2012) revealed that 72.9 percent of communities in Nadowli-Kaleo district had no proper sanitation (toilet) facilities. As earlier indicated, Ghana is one of the ten countries with the highest age of its population without descent and adequate toilet facilities. The implementation of CLTS was to help effect changed behaviour and bring about ODF environment amongst the population. Mosler (2012) indicated that public health practitioners, policy stakeholders and practitioner literature on open defecation had increasingly agreed that it is not enough to provide people with water and sanitation hardware. According to the UNICEF reports after the implementation of CLTS program in Nadowli-Kaleo District, 34 percent of households in the communities adopted and sustained ODF innovation, while 32 percent of households started the program but relapsed to open defecation (OD) and 34 percent of households did not adopt the program and still prefer defecating openly (UNICEF, 2014). It is against this background that this study sought to find out why people adopt new sanitation practices and sustain it while others do not in the Nadowli-Kaleo District of the Upper West region. This will help reduce if not eliminate diseases related to open defecation and improve the health statuses of the people.

\section{Purpose of the study}

The main purpose of the study was to identify the determinants that stimulate patterns of behaviour change in the adoption of ODF innovation in the Nadowli-Kaleo District. Specifically, the study sought to:

- Explore why some people adopt ODF innovation and sustain it.

- Determine the differences in perceptions by people about the adoption and sustenance of ODF innovation in the Nadowli-Kaleo District.

- Determine the perceived effects of sustaining an ODF innovation in society.

\section{Research design and methodology}

A qualitative research design was employed for the study. Qualitative research methods give an understanding of the situation in its uniqueness, presenting what respondents perceive about the situation and what their meanings are (Patton, 2002). Specifically, a phenomenological approach was used because it provides a description of what people experience and how they experience it (Patton, 2002). The phenomenological approach is useful because it provides complex descriptions of how respondents 
experience a phenomenon being studied (Mack, Woodsong, Macqueen, Guest \& Namey, 2005). The approach helped to explore the thoughts and perceptions of members of households on the adoption of CLTS as a new sanitation approach in Nadowli-Kaleo district.

\section{The study population and sampling techniques}

The target population for this study comprised of members of households in Nadowli-Kaleo district, which adopted new sanitation practices and sustained it, as well as households, which rejected the sanitation innovation. They consisted of young and old as well a male and female in Nadowli-Kaleo district of Upper West region of Ghana.

The study used a multi-stage sampling strategy to select the respondents. To begin with, the District was divided into seven Area Councils based on the geographical location of the various communities: Jang, Nadowli, Sankana, Chrikpong, Nator, Sombo and Kaleo. Secondly, purposive sampling was used to select four intervention communities from each of the seven area councils. Households were then stratified into sustained, un-sustained and non-adopter groups based on the post CLTS implementation reports by UNICEFF (2014). Nine households (3 sustained, 3 un-sustained and 3 non-adopters) were randomly selected using the lottery method from each community. Eighty-four households of respondents were selected from each category making a total of 252 respondents as sample size for the study from a sample frame of 550-total households where the CLTS program was piloted. Selection of respondents for the study was voluntary. Nine key informants were randomly selected for the purpose of the study.

\section{Instruments of data collection}

An interview guide using open-ended questions, documentary sources, observation and key informant interviews were the instruments used for data collection. The interview guide was developed based on extensive review of the relevant literature and the objective of the study. A 4-point Likert Rating Scale (LRS) of Strongly Disagree, Disagree, Agree, and strongly agree was used to collect data. Descriptive statistics was used to analyse data collected for objective one and three. The data were analysed using means, standard deviations, frequencies and ages. The Statistical Package for Social Sciences (SPSS) and Microsoft excel were used to analyse the data.

\section{Results and discussions}

The results assess the adoption of new sanitation practices in Nadowli-Kaleo district. In the first place, the demographic characteristics of the respondents are discussed. Secondly the results on why some people adopt new sanitation practices will be presented. This will be followed by a discussion on the factors that affect the adoption and sustenance of new sanitation innovation in the Nadowli-Kaleo district and finally the effects of sustaining behaviour change in the adoption of ODF in society will be presented.

\section{Demographics of respondents}

There are 114 males and 138 females representing 45 per cent and 55 per cent respectively. This result is a close approximation of the structure of the population in the district with respect to sex. The 2010 Population and Housing Census district report (GSS, 2012) puts the total population of the Nadowli district at 94,388. Out of this 44,724 (47.4 percent) are males and 49,664 (52.6 percent) are females. The sex distribution of the population has some implications for socio-economic and demographic development as well as for labour force and gender related activities in the district (GSS, 2012). On age distribution, the age bracket of 31-45 years constitutes the highest proportion (42.7 percent) of the total of 252 respondents. The number of respondents found between the ages of 46-60 is the second highest, constituting 26.8 percent. This is followed by respondents between the ages of 15-30, which represent 25 percent and finally the respondents from age 60 and above recorded 4.5 percent. 


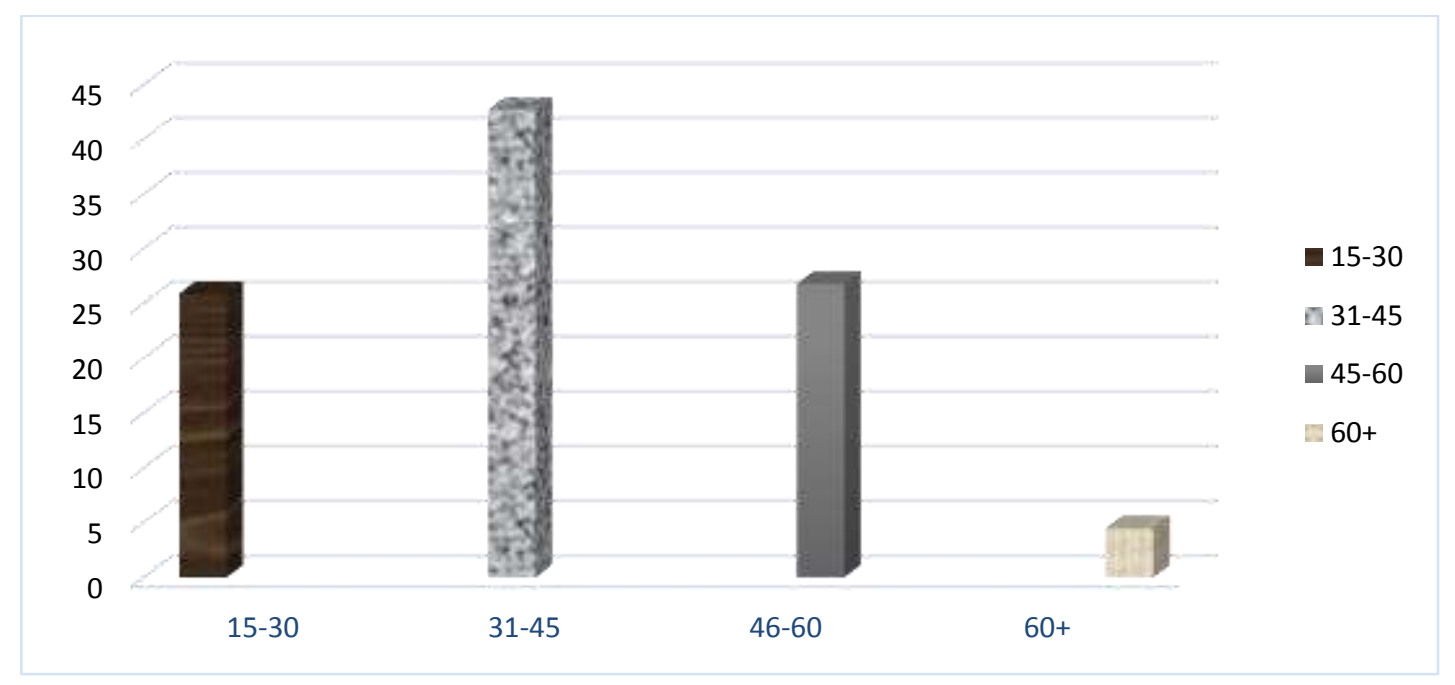

Figure 1. Age of respondents

Table 4.1 illustrates that a large majority of the respondents (64.7 percent) were married while 24.6 percent and 10.7 percent were single and widowed respectively. The data also depicts that a large majority of the respondents (74.6 percent) were Christians, while 15.5 percent practiced African traditional religion and the remaining (9.9 percent) were Muslims. Further analysis also revealed that, 10.7 percent attained primary/middle school education, and 13.8 percent had SHS/Ordinary level education. Only 6.4 percent of the respondents' attained tertiary education and finally 61.9 percent had no formal education, whiles 7.2 percent had non-formal education.

Table 1. Descriptive statistics on salient demographic characteristics of respondents

\begin{tabular}{|l|l|l|}
\hline Variables & Frequency & age \\
\hline Marital status & & \\
Single & 62 & 24.6 \\
Married & 163 & 64.7 \\
Widowed & 27 & 10.7 \\
\hline Total & $\mathbf{2 5 2}$ & $\mathbf{1 0 0}$ \\
\hline Religious denomination & & \\
Christian & 188 & 74.6 \\
Muslim & 25 & 9.9 \\
Traditional & 39 & 15.5 \\
\hline Total & $\mathbf{2 5 2}$ & $\mathbf{1 0 0}$ \\
\hline Level of education & & \\
Primary/JHS/Middle & 27 & 10.7 \\
SHS/O level & 35 & 13.8 \\
Tertiary & 16 & 6.4 \\
Non-formal & 18 & 7.2 \\
No formal education & 156 & 61.9 \\
\hline Total & $\mathbf{2 5 2}$ & $\mathbf{1 0 0}$ \\
\hline
\end{tabular}




\section{Reasons people adopt new sanitation practice and sustain it}

Table 2 below demonstrates that respondents strongly agreed with a modal value of four (4) to the influence of following variables on the adoption of ODF: participation in CLTS activities, levels of education, age of respondents, income levels of respondents and punishment as a deterring tool, that influence them to sustain the adoption of ODF innovation. About 56 percent of respondents "strongly agree" that participation in CLTS program had contributed to the sustainability of ODF innovation. They claimed that the awareness created through participation in CLTS, gave them knowledge on health implication of open defecation. The study findings are similar to Kar's (2003) assertion that CLTS approach had empowered people through participation in India to analyse the extent and risk of environmental pollution caused by open defecation and that has affected their sanitary behaviour positively. Participation in ODF program was supposed to influence participants to make their own choices as to the type of toilet facilities they want to construct and to climb the sanitation ladder in future.

\section{Table 2. Respondents reason for adoption and sustenance of ODF innovation.}

\begin{tabular}{|c|c|c|c|c|c|c|c|c|c|}
\hline \multirow[t]{2}{*}{ Statement } & \multicolumn{2}{|c|}{$\begin{array}{l}\text { Strongly } \\
\text { Disagree (1) }\end{array}$} & \multicolumn{2}{|c|}{ Disagree (2) } & \multicolumn{2}{|c|}{ Agree (3) } & \multicolumn{2}{|c|}{$\begin{array}{l}\text { Strongly } \\
\text { Agree (4) }\end{array}$} & \multirow[t]{2}{*}{$\begin{array}{l}\text { Mean } \\
\text { Mark }\end{array}$} \\
\hline & Freq. & $\%$ & Freq & $\%$ & Freq & $\%$ & Freq. & $\%$ & \\
\hline $\begin{array}{l}\text { Does participation affects the adoption of } \\
\text { ODF? }\end{array}$ & 6 & 2.3 & 6 & 2.3 & 99 & 39.3 & 141 & 56.1 & 4 \\
\hline $\begin{array}{l}\text { Does level of education of affect behaviour in } \\
\text { ODF adoption? }\end{array}$ & 36 & 14.3 & 18 & 7.1 & 84 & 33.3 & 114 & 45.3 & 4 \\
\hline $\begin{array}{l}\text { Does access and quality of toilet facilities } \\
\text { influence usage? }\end{array}$ & 00 & 00.0 & 33 & 13.1 & 148 & 58.7 & 71 & 28.2 & 3 \\
\hline $\begin{array}{l}\text { Does age influence behaviour in ODF } \\
\text { adoption? }\end{array}$ & 34 & 13.5 & 20 & 7.9 & 28 & 11.1 & 170 & 67.5 & 4 \\
\hline $\begin{array}{l}\text { Does distance to the toilet facility influences } \\
\text { people's adoption behaviour? }\end{array}$ & 50 & 19.8 & 33 & 13.1 & 139 & 55.2 & 30 & 11.9 & 3 \\
\hline $\begin{array}{l}\text { Does incomes affect adoption and sustenance } \\
\text { of ODF innovation? }\end{array}$ & 4 & 1.6 & 3 & 1.2 & 45 & 17.9 & 200 & 79.3 & 4 \\
\hline $\begin{array}{l}\text { Does sex influence the change behaviour in } \\
\text { ODF adoption? }\end{array}$ & 2 & 0.8 & 8 & 3.2 & 195 & 77.3 & 47 & 18.7 & 3 \\
\hline $\begin{array}{l}\text { Does motivation influence peoples' change } \\
\text { behaviour to practice ODF? }\end{array}$ & 6 & 2.4 & 19 & 7.5 & 142 & 56.3 & 85 & 33.8 & 3 \\
\hline $\begin{array}{l}\text { Does persuasive communication lead to } \\
\text { collective adoption of ODF? }\end{array}$ & 14 & 5.6 & 35 & 13.9 & 155 & 61.5 & 48 & 19.0 & 3 \\
\hline $\begin{array}{l}\text { Does religion influence the adoption and } \\
\text { sustenance of households' behaviour on } \\
\text { ODF? }\end{array}$ & 20 & 7.9 & 30 & 11.9 & 170 & 67.5 & 32 & 12.7 & 3 \\
\hline $\begin{array}{l}\text { Does “'name of shame' affects household's } \\
\text { changed behaviour on ODF adoption? }\end{array}$ & 2 & 0.8 & 48 & 19.0 & 25 & 9.9 & 177 & 70.3 & 4 \\
\hline
\end{tabular}


Respondents were asked if they agree that the level of education has an influence on their behaviour towards the adoption and sustenance of ODF innovation. Table 2 shows that 7.1 percent of the respondents "disagreed" that level of education has an influence on sustainable behaviour change in the adoption of ODF innovation but 45.3 percent of the respondents "strongly agree" that the level of education of an individual has an influence on his/her behaviour when they are adopting ODF innovation. Educated respondents living in these same communities have constructed, maintained and used their toilet facilities than those who had no formal education. These findings are in line with Kar's (2003) view that, knowledge of the health implication of open defecation by households, influence their desire to sustain the adoption of ODF.

The table also illustrates that about 13.5 percent of the respondents "strongly disagree" that age has an influence on the adoption and sustenance of ODF innovation. Also 7.9 percent of the respondents "disagree" that age could influence their behaviour on ODF adoption and sustenance, while 11.1 percent of the respondents "agree" that age has an influence on their behaviour in the adoption and sustenance of ODF. Again 67.5 percent of the respondents with the modal mark of four (4) "strongly agree" that age influenced their decision to adopt and sustain ODF innovation. The youth are more passionate and active in constructing and using sanitation facilities. How old or young a respondent is, has an influence on his/her likelihood of adoption and sustenance of an innovation. Respondents in this group who are between the ages of 31-45 tend to be more active and willing to use indigenous materials to construct toilets and also take risks in new development interventions. The study findings shows that the age groups from 15-60 are those who had adopted changed behaviour in ODF innovation therefore, age of an individual significantly influence the adoption of ODF innovation.

The evidence here is that respondents between the age groups of 15-30 and 31-45 are those who are willing to sustain ODF innovation. This age group maintains the toilets facilities and cleans them regularly. When asked if sex of a respondent has an influence on a person's ability to adopt and sustain ODF, large majority of the respondents (77.3 percent) “agreed" that sex influenced their decision to adopt sustainable ODF innovation. Miss Rabiatu an assembly woman of Nator electoral area indicated that;

"Gender influences ones desire to adopt and sustain ODF practice. Females tend to have more concern about their privacy, safety, dignity and comfort hence their desire to sustain ODF than their male counterparts. The females, therefore, will wish that there are toilet facilities in every housebold".

On the other hand, 3.2 percent of the respondents "disagree" and reported that sex has no influence on their decision to adopt and sustain ODF behaviour. Table 2 further shows that 79.3 percent "strongly agree" that incomes of respondents play a significant role in the construction of toilet facilities and therefore influence the behaviour of people on the adoption and sustenance of ODF practice. Those who have high incomes reported changes in their behaviour towards sanitation. This finding affirms the study conducted in Bhadrak, Orissa in India on "promoting latrine use" by Pattanayak et al. (2007) which revealed that, there is a positive correlation between household latrine adoption rate, and sanitation change behaviour and household wealth status.

About 56 percent of the respondents also "agree" that incentives or motivation in the form of certificates help in the adoption and sustenance of an innovation. Incentives for attaining ODF status played a significant role in sustaining ODF innovation. Respondents, however, indicated that the incentives or rewards should not be in monetary form in order to prevent the creation of a divisive society. They stated that durbars could be organized in honour of those who obtained ODF status. During observation, it was revealed that, incentives in the form of certificates given to those who sustain the adoption of ODF innovation by the district sanitation officers had motivated others to construct their own toilet facilities in order for them to also gain such recognition. However, 7.5 percent of the respondents "disagree" that incentives have influence on their behaviour as far as the adoption and sustenance of ODF innovation is concerned. Table two (2) further shows that majority of respondents (70.3 percent) "strongly agree" that 
punishment for non-adopters of ODF has positively influenced the adoption of ODF innovation. Respondents strongly agreed that meting out punishment like "name and shame" to non-adopters of ODF by members of a social system positively influence the adoption and sustenance of ODF. The findings support that of Kar (2003) who indicated that the CLTS approach plays on the emotions of community members through "walk of shame".

Table 2 also indicates that 58.7 percent of respondents "agree" with a modal value of three (3) that access and quality of toilet facilities motivate them to sustain their behaviour in the adoption of ODF. This reinforces the view that respondents hold the perception that if toilet facilities are available with an appreciable quality, it motivates them to adopt and sustain their behaviour as far as ODF practice is concerned in the area. Apart from access and quality of the toilet facility, 55.2 percent of the respondents "agree" that distance to the toilet facility has an influence on the adoption and sustenance of an ODF innovation. They stated that if the distance to the toilet facility is farther from their homes the higher the risk for women who are likely to be raped on their way to and from the toilet site. They will prefer the sanitation facilities to be closer to their homes to facilitate continuous use. Respondents were asked if persuasion by the change agents had led to collective adoption of ODF innovation. About 56 percent of the respondents "agree" that persuasive behaviour change communication (BCC) strategies like drama, role-play, sanitation songs had led to collective adoption and sustenance of ODF innovation. They indicated that, the BCC strategies adopted during the ODF innovation diffusion period had contributed immensely to its adoption and sustenance. During one-on-one interview, a key informant in Charisombo village reported how a facilitator stood in the middle of a defecation site and took a scoop of faeces on one plate and asked a participant to bring a plate of food and kept the two next to each other. Flies constantly flew from one plate to the other. The facilitator then offered the plate of food to participants and asked if they would eat it, which evoked a lot of disgust. The facilitator told the participants that this is exactly what flies' do to their food and that they are constantly ingesting each other faeces. He added that this BCC strategy had encouraged a collective response in the adoption and sustenance of ODF innovation.

This is a classic approach that defines CLTS. It is the immediate decoding of revulsion, which is expected to trigger attitudinal change.

\section{Religion and adoption of ODF innovation}

An interesting feature of the results is that when respondents are grouped by faith, the per cent of adoption among faith groups differ significantly. Religion became a key determinant of adoption of ODF innovation. While the total number of Muslims out of the total sample size is just 25 being 9.9 percent, the rate of adoption among Muslims is as high as 56 percent. On the other hand the corresponding age among Christians 42 with African Traditional Religion trailing at 2 percent. Mr. Daniel Dong indicated that:

\section{Muslims among the respondents indicated that constructing toilet facilities in their homes was to help their wives and daughters most especially, to have their privacy when they visit the toilet facility and also to wash their anus regularly as demanded by their religious practice.}

Muslims therefore show most sustained change behaviour in ODF adoption. This assertion is in tandem with Avvannavar \& Mani (2008), they pointed out that Muslims constantly practice anal cleansing with water after defecation and that this practice can be done in comfort in a confined place. Also 2 percent of the respondents who are African traditional worshipers disagree and stated that religion does not influence their behaviour in the adoption ODF innovation.

\section{Economic perceptions that promote the adoption of ODF in Nadowli-Kaleo district}


Table 3 illustrates that large majority of respondents with a sum of score (163) and a mean rank of (1.53) mentioned income levels as the most ranked economic perception that influence people to adopt and sustain ODF behaviour. Majority of the respondents indicated that their income levels have significant influence on their ability to construct and maintain their toilet facilities.

Table 3: Economic perceptions that promote the adoption of ODF in Nadowli-Kaleo district

\begin{tabular}{|l|l|l|l|}
\hline Perceptions & $\begin{array}{l}\text { *Sum } \\
\text { scores }\end{array}$ & Mean Rank & Rank \\
\hline Economic perceptions & & & \\
\hline Income levels & 163 & 1.53 & 1 \\
\hline Incentives for practicing ODF & 220 & 2.58 & 2 \\
\hline Cost of construction and maintenance & 289 & 3.39 & 3 \\
\hline Type of occupation latrine & 341 & 3.55 & 4 \\
\hline Lack of credit to support & 684 & 5.95 & 5 \\
\hline Access and types of latrines & 614 & 6.60 & 6 \\
\hline
\end{tabular}

*Multiple responses

Again incentives for practicing ODF emerged as the second most important perceptive with a mean rank of 2.58. Incentives influence people to adopt and sustain ODF innovation. The respondents indicated that, when people who attain ODF status are rewarded in the form of certificates during durbars, it serves as motivation for others to attain the ODF status. On the issue of cost of construction and maintenance of the latrines, majority of the respondents with a mean rank of 3.39 consider that as a key motivating perception in the adoption and sustenance of ODF. If the types of available toilets are less costly to construct, coupled with high-income levels, they will be willing to construct, maintain and sustain its use.

Table 3 again shows minority of respondents with the sum of scores (314) and mean rank of 3.55 indicated that the type of occupation determines the sustainability of behaviour change in the adoption of ODF. If they have secured jobs with regular incomes it can motivate them to construct and maintain their latrines and that will lead to sustained sanitary behaviour. Credit to support latrine construction with mean rank of 5.95 was identified as a perception motivating the sustainability of attitudinal change in the adoption of ODF innovation. Table 3 further illustrates that, respondents agrees with the least mean rank of 6.60 and sum of scores of 614 that access to toilet facilities motivate sustainable behaviour change in the adoption of ODF innovation.

\section{Educational perceptions that promote the adoption of ODF}

Table 4 illustrates that behaviour change communication strategies like drama, flyers and sanitation songs played an important role in the adoption and sustenance of ODF and therefore, ranked $1^{\text {st }}$ with a mean rank of 1.90. The sum of score of 173 indicates that majority alluded to this assertion. They stated that the BCC strategy effectively employed in triggering CLTS program had encouraged holistic participation by community members. The position held by the respondents is similar to earlier study conducted by McConville (2008) in which she stated that behaviour change communication strategy, is an important tool, which when employed could lead to achieving health benefits from sanitation programs. 
Table 4 Educational perceptions that promote the adoption of ODF in Nadowli-Kaleo district

\begin{tabular}{|l|l|l|l|}
\hline Perception & *Sum of Scores & Mean & Rank \\
\hline Behaviour Change Communication Strategy & 173 & 1.9 & 1 \\
\hline $\begin{array}{l}\text { Behaviour change messages rather than building free } \\
\text { toilets }\end{array}$ & 245 & 3.11 & 2 \\
\hline Sanitation campaigns & 399 & 3.32 & 3 \\
\hline Awareness on smell-free latrines & 432 & 3.69 & 4 \\
\hline
\end{tabular}

*Multiple responses

Again Table 4 shows that majority of the respondents with the mean rank of 3.11 indicated that behaviour change messages (ranked $2^{\text {nd }}$ ) given to them during triggering period rather than construction of toilet facilities motivated them to adopt and sustain ODF innovation. The third ranked perceptive was campaigns on sanitation change behaviour with the mean rank of 3.32. Respondents advocated for the need for more sanitation campaigns, which will expose participant to affordable latrines. Information on the negative effects of open defecation should be disseminated properly to the people. "The essence of the diffusion process is the information exchange through which an individual communicates a new idea to one or several others" (Rogers, 1995, p. 18). Respondents indicated that sanitation campaigns had changed long-held practice and norm of not publicly mentioning faeces in public thereby impeding public discourse on toilets. The campaigns have also addressed needs preferences and behavioural pattern of children, women and men to allow for positive attitudinal change towards proper management of faecal waste.

\section{Socio-cultural perceptions that promote the adoption of ODF}

Gender and socially inclusive programs (sum of score 136) in the process of CLTS implementation with the mean rank 2.64 was identified as the most important socio-cultural factor that promotes sustainable behaviour change in sanitation practices. The rank shows that the involvement of both men and women in the implementation process helps to attain project sustainability.

Table 5 Socio-cultural perceptions promoting the adoption of ODF in Nadowli-Kaleo district

\begin{tabular}{|l|l|l|l|}
\hline Perception & *Sum of Scores & Mean & Rank \\
\hline Gender inclusive process & 136 & 2.64 & 1 \\
\hline Prestige & 341 & 2.93 & 2 \\
\hline Attitude towards participation & 461 & 4.27 & 3 \\
\hline Sanctioning open defecators & 848 & 4.88 & 4 \\
\hline Resistance to adoption & 891 & 6.96 & 5 \\
\hline Religious/belief system & 902 & 7.25 & 6 \\
\hline
\end{tabular}

*Multiple responses 
As Table 5 shows that the second most important socio-cultural perceptive influencing changed behaviour in sanitation practices was prestige with the mean rank of 2.93. Prestige acquired in adopting sustainable behaviour change in ODF had served as a morale booster. Table 5 further indicates that the third most important perception motivating people to change their behaviour is attitudes towards participation during the introduction of CLTS program. The attitudinal change programs had taken into consideration the values, culture and beliefs of the communities and experiences which had led to the desired results. The CLTS program implementation agents also addressed the myths, attitudes, beliefs and distorted perceptions of separate bathing places and toilet facilities for women and men because of taboos that do not allow them to use the same toilet facilities. Finally, sanctioning open defecators was ranked fourth with a mean rank of 4.88 as a key motivating perception. This implies that punishing those who practice open defecation had discouraged people from practicing open defecation.

\section{Environmental perceptions that promote the adoption of ODF}

Table 6 presents information on environmental perceptions that motivate people to adopt and sustain changed behaviour in sanitation practices. Perceptions like health status, sanitation facilities, distance, nature of land and proximity of forest were ranked to get the agreement among the ranks. Table 6 below is the summary of the ranks.

\section{Table 6 Environmental perceptions that affect the adoption of ODF in Nadowli-Kaleo district}

\begin{tabular}{|l|l|l|}
\hline Item & Mean rank & Rank \\
\hline Environmental & & \\
\hline Heath status & 1.58 & 1 \\
\hline Sanitation facility & 2.34 & 2 \\
\hline Distance to sanitation facility & 3.94 & 3 \\
\hline Nature of land & 4.12 & 4 \\
\hline Proximity to the forest & 7.30 & 5 \\
\hline
\end{tabular}

Source: Field Survey, 2014.

Environmental cleanliness was perceived to constitute the most important factor motivating people to adopt and sustain ODF innovation. This was ranked first with the mean rank of 1.85. Environmental cleanliness leads to improve health status. This is followed by quality of the sanitation facility, which was ranked the second most important factor that motivated them to sustain open defecation free environment. Regular maintenance of latrines by those who have their personal latrines will lead to help good quality latrines, and thus encourage sustained use. Furthermore, distance to sanitation facility was the third most important environmental factor with a mean rank of 3.94 motivating sustainable ODF behaviour. Because their personal toilet facilities are situated closer to their homes, it was easier to sustain the use of the latrines, leading to sustained changed behaviour. It will also alley the fears of being attacked on their way to the toilet facilities since they have their facilities not far away from their houses. Table 6 further shows that the nature of land in their area with a mean rank of 4.12 influenced the sustained adoption of ODF innovation. The land is not waterlogged as such their latrines are not destroyed during raining season and also their latrines do not get filled up with underground water.

\section{Effects of sustaining and not sustaining ODF Adoption}


The third objective sought the views of respondents in the study communities on the effects of sustaining the adoption of ODF innovation in Nadowli-Kaleo district. The respondents were asked to indicate the extent to which the perceived effects of sustaining change behaviour in ODF innovation have on their lives in the study area. The results are presented in table 7 below.

Table 7: Effects of Sustaining ODF Adoption in a society

\begin{tabular}{|l|l|l|}
\hline Effects & Frequency & age (percent) \\
\hline Health improvement & 6 & 7.1 \\
\hline Safety & 10 & 11.9 \\
\hline Privacy & 20 & 23.8 \\
\hline Dignity & 14 & 16.5 \\
\hline Clean environment & 13 & 15.4 \\
\hline Continuation of ancestral practice & 4 & 4.5 \\
\hline Soil fertility & 3 & 3.5 \\
\hline Comfort & 14 & 16.6 \\
\hline Total & 84 & 100 \\
\hline
\end{tabular}

In analysing the effects of adopting sustainable behaviour change on ODF innovation, the study unearthed the following as presented in Table 7. The study found that health issues do not usually come across as the top effect of adopting sustainable behaviour change on ODF innovation by most rural people in NadowliKaleo district. The positive effects for adopting sustainable behaviour change on ODF innovation included privacy, comfort, clean environment, safety (security) for women and dignity. On the issue of health improvement, minority of the respondents ( 7 percent) mentioned that health benefits and freedom from diarrhoea contributed to the adoption of sustainable behaviour change in ODF innovation. This finding is similar to Jenkins and Scott (2007), who indicated that prestige, and dignity and not health are rather listed as the key benefits of toilet use. Table 7 further indicates that 23.8 percent of the respondents mentioned privacy as a major effect of adopting sustainable behaviour change in ODF practice. Privacy is a uniformly celebrated quality among the selected communities. It was observed during the interviews that people prefer not to be seen, especially by other gender or people of other age groups. Madam Akosua, a 'natural' leader stated that:

we (women) don't have to feel ashamed anymore. We don't have to feel embarrassed when we defecate. We can do it in the privacy of our homes

This statement was predominant during the interview sessions. Other respondents admitted that sustaining behaviour change in ODF has liberated them from shame. Alternatively, they agreed that if they continue to defecate in the open, they will continue to lose their privacy. A female respondent pointed out that:

latrine offers her privacy for defecation, urination, and mensuration management, which allows her to adhere to her faith as a Muslim and avoid the shame of being seen by men during these periods.

Even among non-adopters, location for defecation had changed to ensure privacy. Privacy is followed by comfort representing 16.6 percent as a positive effect for households adopting sustainable behaviour change and owning latrines to practice ODF. According to Mr. Kolo: 
people find it inconvenient to defecate in the bush, because of their vulnerability to weather, privacy and security concerns. During the rainy season, mosquitoes flourish and excessive rainwater makes the ground muddy and unpleasant. Using a latrine provides the advantage of coping with all kinds of weather.

Another positive effect of sustainable behaviour change in the adoption of ODF innovation is safety from risk of snake bites, and rape when they go to the open field to defecate. Table 7 shows that 11.9 percent of the respondents in the sustained group category mentioned safety as a positive effect for households sustaining change behaviour in the adoption of ODF. The fact that they have access to a toilet facility provides a sense of security to respondents and therefore have a positive response to the adoption and sustenance of ODF mostly for women. Also Table 7 indicates that 15.4 percent of the respondents mentioned environmental cleanliness as a positive effect of sustaining behaviour change in the adoption of ODF innovation. While expressing their individual and collective desire to live in a clean environment, they admit that sustaining ODF innovation is an antidote to environmental cleanliness. They further stated that a clean environment, generate a cleaner environment which has led to reduction in diarrhoea and other diseases. About 47 percent of the respondents perceived that sustainable behaviour change in the adoption of ODF innovation is important for community development. This motivates them to sustain behaviour change in the adoption of ODF innovation. UNICEF stated in 2009, that open defecation threatens public health, leads to high expenditure on health care, impacts negatively on social and economic development and increases levels of poverty among rural societies.

\section{DISCUSSIONS}

\section{Reasons people sustain behaviour change in ODF adoption}

This study was undertaken against a backdrop of a report on the adoption of an ODF innovation in the Nadowli-Kaleo District in a CLTS program. The report showed that at the end of the implementation of the CLTS program, 34 per cent of households adopted and sustained the introduced innovations. About 32 per cent relapsed while another 34 per cent rejected the innovation. The central question driving this study was to find out why such an obviously good innovation was overwhelmingly either rejected with a 34 per cent adoption rate. For those who adopted and sustained behaviour change in ODF adoption, 56.1 percent of respondents did so because they gained knowledge on health implications of open defecation through their participation in CLTS programme. Also 28.2 percentof the respondents indicated that access to toilet facilities and quality of latrines were responsible for the sustenance of ODF innovation. Those who adopted but could not sustain and those who did not adopt ODF innovation cited income levels as the main contributor to their inability to adopt and sustain ODF innovation. They indicated that farming is their main occupation (74.5 percent) and the incomes they get from farming are very low. They prefer using the little money they get from farming for other things to maintaining their toilet facilities.

The majority of the respondents ( 81 percent) in the non-adopter group had the opinion that punishing people who did not adopt ODF through the policy of "name and shame" rather discouraged the offenders from adopting ODF innovation and brought about a divisive society, thus making it difficult for them to change their behaviours towards adopting ODF innovation. Finally 90 percent the respondents in the non-adopter group agreed that the adherence of one's religious faith and cultural beliefs determines the adoption of ODF innovation.

\section{(a) Perceptions that promote adoption of ODF}

About 40 percent of the respondents ranked income levels as the most important economic factor motivating them to adopt and sustain ODF. Again BCC strategies such as drama, role play by school children, posters, and durbars on good disposal of faeces used during the triggering period of CLTS 
implementation was ranked as the most important educational factor that promoted ODF innovation adoption. Socio-cultural factors like gender and socially inclusive process in the participatory stage of ODF implementation process were ranked as the most important socio-cultural factors promoting the adoption and sustenance of ODF. Finally, 55 percent of the respondents indicated that environmental cleanliness which leads to improved health status of respondents promote the adoption ODF innovation.

\section{(b) Perceptions that impede the adoption of ODF.}

On the issue of economic factors de-motivating the adoption and sustenance of ODF innovation, the study reveals that 21.8 percent of respondents mentioned cost of construction of latrines as the most demotivating economic factor. Similarly, lack of community awareness on smell-free latrines (34.2 percent) was ranked first as impeding adoption. On the other hand, resistance to change sanitation behaviour (18.8 percent) was ranked as a major impeding socio-cultural factor. About 28 percent of the respondents feared that the latrine holes may collapse and people may fall inside because of the latrines' susceptibility to harsh weather. Such fear is heightened during the raining season and thus serves as the most impeding environmental factor in the adoption and sustenance to ODF innovation.

Quality of latrines will lead to sustained use for various reasons including privacy (22 percent), which form a major positive effect influencing households' decision to own latrines and sustain changed behaviour in the adoption of ODF. People prefer not to be seen, especially by other gender or people or other age groups when defecating.

\section{Conclusion and recommendation}

Community participation in CLTS programme has given respondents much knowledge on health implications on open defecation and this has encouraged them to construct households' latrines. Sustained behaviour change has resulted in the comfort, security or safety, privacy, health and dignity of ODF innovation adopters and has also influenced households' decision to construct and use toilets to achieve ODF.

Also low-income level is a hindrance to the maintenance of household latrines and the practice of ODF innovation on sustainable basis. Punishing people who do not adopt ODF through "naming and shaming" discourages them from adopting ODF innovation. Non-ODF adoption has culminated into filthy environment where flies contaminate drinking water and food with faecal particles leading to common sicknesses like diarrhoea, cholera, and typhoid. The continued attachment to ancestral links because of culture and tradition has impeded the adoption of ODF innovation and perpetuated the practice of open defecation (OD) in the district.

The adoption and sustenance of ODF in the study area is promoted mainly by messages using behaviour change communication processes, affordable cost of constructing latrines, gender and socially inclusive process and improvement in the health statuses of respondents. On the other hand, cost of construction of latrines (economic), lack of awareness on smell-free latrines (educational), household resistance to new innovation (socio-cultural) and quality of the sanitation facilities (environmental) are factors that impede sustainable behaviour change in the adoption of ODF.

In view of the fact that, some households attribute cultural beliefs to the unwillingness to own household latrines and sustain behaviour change in ODF innovation, it is recommended that stakeholders in the WASH sector intensify education to eliminate the cultural fear of people in the use of latrines. The education should be done in collaboration with the traditional leaders where the traditional leaders are given the lead role in the triggering process of the CLTS implementation stage in order to reduce resistance from communities and promote acceptance. 
It is recommended that BCC strategies like interpersonal communication, mass media and community and cultural networks be intensified to encourage collective response in the adoption and of ODF innovation to avoid diseases outbreak.

\section{REFERENCES}

Avvannavar, S. M., \& Mani, M. (2008). A conceptual model of people's approach to sanitation. Science of the Total Environment, 390(1), 1-12. http://doi:10.1016/j.scitotenv.2007.09.018

Baur, P., and M. Woodhouse (2004). Enhancing Private Sector in Rural Water Supply: An Action Oriented Study. Available at: http://www.gwclim.org/presentations/session1/baur.pdf. (Accessed on August 7, 2012).

Cairncross, A. (2003). Sanitation in the Developing World: Current Status and future Solutions. International Journal of Environmental Health Research, 13(1), S123-S131.

Ghana News Agency - GNA (2012). Ghana President Mahama launches massive National Sanitation Programme. Available at: http://ghananewsagency.org/health/president-mahama-launches-nationalsanitation-programme-49091. (Accessed June 21, 2018)

Ghana Health Service (2016). The Health Sector in Ghana. Facts and Figures. Ghana, Accra. Available at: http://www.ghanahealthservice.org/ghs-item-details.php?cid=5\&scid=55\&iid=135 $\quad$ (Accessed on April 30, 2018)

Ghana Statistical Service (2012). 2010 Population and Housing Census: Final Report, Brief Note. Ghana Statistical Service, Government of Ghana, Accra.

IIED (2010). Participatory Learning and Action- Tales of Shit: Community-Led Total Sanitation in Africa. London: Park Communications Ltd.

McConville, J. R. (2008). "Sustainable approaches to sanitation planning and implementation in West Africa. An empirical test of the Sadharanikaran Communication Theory to defecation hygiene behavior: Evaluation of a child-to-community Intervention in Maharashtra, India." PhD Thesis submitted to the School of Hygiene and Public Health of the Johns Hopkins University, Baltimore, Maryland.

Jenkins, M. W. \& Scott B. (2007). Behavioral indicators of household decision-making and demand for sanitation and potential gains from social marketing in Ghana. Social Science \& Medicine 64 (2007) 2427 - 2442

JMP (2017). Progress on drinking water, sanitation and hygiene, Update on SGD baselines, WHO and UNICEF. Available at https://washdata.org/reports (accessed on April 29, 2018)

Kar K. and Chambers R. (2008). Handbook on community led total sanitation. Plan and Institute of Development Studies, Sussex, UK: University of Sussex. http://www.communityledtotalsanitation.org/resource/handbookcommunity-led-total-sanitation. (Accessed June 21, 2018).

Kar, K. (2003). Subsidy or self-respect? Participatory total community sanitation in Bangladesh, IDS working paper series. Sussex, England: Institute of Development Studies.

Kleemeier, E. (2001). Rural water sector reform in Ghana: a major change in policy and structure. Water and sanitation program-Africa Region (WSP-AF). The World Bank, Hill Park, Upper Hill, Nairobi, Kenya.

Mack, N., Woodsong C., Macqueen., M. K., Guest, G., \& Namey, E. (2005). Qualitative research methods: A data collector's field guide. North Carolina, USA: Family Health International. 
MLGRD \& MWRWH. (2009). Water, Sanitation and Hygiene (WASH); Behaviour Change Communication (BCC) Strategy for the Urban Sub Sector, Ghana: Ministry of Local Government and Rural Development, and Ministry of Water Resources, Works and Housing, Government of Ghana, Accra.

Moe, C. L. \& Rheingans, R. D. (2006). Global challenges in water, sanitation and health. Journal of Water and Health Dec 2006, 4 (S1) 41-57

Mosler, Hans-Joachim (2012). A systematic approach to behavior change interventions for the water and sanitation sector in developing countries: a conceptual model, a review, and a guideline. International Journal of Environmental Health Research, 22:5, 431-449, DOI: 10.1080/09603123.2011.650156

Mukherjee, N; Robiarto, A; Saputra, E., and Djoko W. (2012) Achieving and sustaining open defecation free communities: Learning from East Java. Water and Sanitation Program https://www.wsp.org/sites/wsp.org/files/publications/WSP Indonesia Action Research Report.pd $\underline{f}$ (accessed on April 30, 2018).

Pattanayak, S. K., Dickinson, K. L., Yang, J.-C., Patil, S. R., Praharaj, P., \& Poulos, C. (2007). Promoting latrine use: Midline findings from randomized evaluation of a community mobilization campaign in Bhadrak, Orissa. Bhadrak, Orissa.

Patton, M. Q. (2002). Qualitative research and evaluation methods. Thousand Oaks, CA: Sage Publications.

Rogers, E.M. (1995). Diffusion of innovations 4th Edition. New York: Free Press.

UNICEF. (2014). Progress Reports on the Implementation of CLTS in the Nadowli/Kaleo District. UNICEF and Nadowli District, Nadowli/Kaleo District Assembly.

UNICEF (2009). Community approach to total sanitation; Based on case studies from India, Nepal, Sierra-Leon, Zambia. UNICEF: New York, USA. http://www.communityledtotalsanitation.org/resource/communityapproaches-total-sanitation-case-studies-india-nepal-sierra-leone-zambia. Accessed on June 21, 2018

WaterAid (2017). Out of Order: The state of the world's toilets, 2017. WaterAid, www.wateraid.org Accessed on November 25, 2017.

Wellington, N. L, Larbi, E. \& Appiah, J. (2011). Innovative approaches to implementing CLTS in an urban setting: Successful lessons from piloting the approach in a small town of Lekpongunor in the Dangme West District of Ghana. Available at: http://www.communityledtotalsanitation.org/sites/communityledtotalsanitation.org/files/Urban CL TS Ghana.pdf. (Accessed on April 30, 2018)

WSP (2012). Economic Impact of Poor Sanitation in Africa Environ Health Insights. Volume.5; 2011; 5: 63-70. doi:10.4137/EHI.S8199 PMCID: PMC3212862.

WHO/UNICEF (2003). Meeting the Millennium Development Goals for drinking water and sanitation target. A midterm assessment of progress. Geneva: World Health Org and United Nations Children's Fund 